\title{
BMJ Open Disparity in pre-emptive end-of-life conversation experience caused by subjective economic status among general Japanese elderly people: a cross- sectional study with stratified random sampling
}

\author{
Tomoo Hidaka (D) , ${ }^{1}$ Shota Endo, ${ }^{1}$ Hideaki Kasuga, ${ }^{1}$ Yusuke Masuishi, ${ }^{1}$ \\ Takeyasu Kakamu (D) , ${ }^{1}$ Tomohiro Kumagai, ${ }^{1}$ Keiko Saito, ${ }^{2}$ Kouichi Abe, ${ }^{3}$ \\ Tetsuhito Fukushima ${ }^{1}$
}

To cite: Hidaka T, Endo S, Kasuga $\mathrm{H}$, et al. Disparity in pre-emptive end-of-life conversation experience caused by subjective economic status among general Japanese elderly people: a crosssectional study with stratified random sampling. BMJ Open 2019;9:e031681. doi:10.1136/ bmjopen-2019-031681

- Prepublication history for this paper is available online. To view these files, please visit the journal online (http://dx.doi org/10.1136/bmjopen-2019031681).

Received 15 May 2019 Revised 26 August 2019 Accepted 05 September 2019

Check for updates

(c) Author(s) (or their employer(s)) 2019. Re-use permitted under CC BY-NC. No commercial re-use. See rights and permissions. Published by BMJ.

For numbered affiliations see end of article.

Correspondence to

Tomoo Hidaka;

thidaka@fmu.ac.jp

\section{ABSTRACT}

Objectives Pre-emptive conversations (PCs) about end-oflife $(\mathrm{EOL})$ preferences are beneficial for both elderly people and their families to understand and share the preferences. However, the factors which promote/inhibit PCs have yet to be clarified. We therefore aimed to determine the factors related to having PCs with hypothesis that age, subjective economic status and subjective health status are associated with having PC experience.

Design A cross-sectional study administering a questionnaire and using stratified random sampling by gender and region.

Setting Residents aged 65 years or older who were not receiving nursing care as of 1 November 2016, were extracted from the Japanese long-term care insurance system registry in Koriyama City, Fukushima Prefecture, Japan.

Participants 1575 participants (717 males and 858 females).

Outcome Presence or absence of PC experience with family or friends (yes/no).

Results The mean age of the participants was 74.0 years. A multivariable logistic-regression analysis revealed that having $\mathrm{PC}$ experience was significantly associated with gender $(\mathrm{OR}=1.907 ; 95 \% \mathrm{Cl}=1.556$ to $2.337 ; \mathrm{p}<0.001)$, subjective economic status ( $\mathrm{OR}=0.832 ; 95 \% \mathrm{Cl}=0.716$ to $0.966 ; \mathrm{p}=0.016)$ and subjective happiness $(\mathrm{OR}=0.926$; $95 \% \mathrm{Cl}=0.880$ to $0.973 ; p=0.003$ ).

Conclusions Poor subjective economic status of elderly people may result in the absence of EOL conversation experience with their families and friends, hindering the elderly from sharing and understanding the EOL preferences. To promote PCs about EOL, gerontology and public health professionals should give special consideration to the subjective economic status of elderly people.

\section{INTRODUCTION}

Understanding and respecting the end-oflife (EOL) care preferences of the elderly

\section{Strengths and limitations of this study}

- This study was designed to determine the factors related to having pre-emptive conversation about end-of-life, using subjective assessments of economic/health status among elderly people, which are robust predictors of health, including health-related behaviour.

- This study targeted the general Japanese elderly population, who accounted for $27.7 \%$ of the total population as of 2017. With the premise that other developed countries will soon have an ageing population as in Japan, this study provides generalisability.

- This study provides a more accurate representation of the general population than previous studies, due to the use of a stratified randomised sampling model that reduces sampling bias.

- The samples were obtained from a single city in Japan, and future research should be conducted using study populations from multiple regions, in order to obtain even more accurate results than those of the present study.

population is a major issue of gerontology and public health in ageing societies. The fundamental value in EOL care is respect for a person's autonomy ${ }^{1}$; however, a recent study reported that approximately $70 \%$ of elderly people at the EOL stage were incapable of autonomous decision making. ${ }^{2}$ Holding a conversation regarding EOL care preferences before a person actually reaches the EOL stage is important for understanding the person's EOL wishes, because family members often play the role of surrogate, representing such elderly relative's wishes in 
the event that he/she has become unable to communicate coherently. ${ }^{3}$

Rafferty et al called conversations about EOL 'pre-emptive conversations (PCs)', ${ }^{4}$ and these conversations are conceptualised as a preventative health behaviour, helping individuals minimise unwanted medical treatments and maximise their quality of life. ${ }^{5}$ Although PCs about EOL are expected to be beneficial for both elderly people and their families, it is not widely practiced. For example, recent research has indicated that nearly $40 \%$ of elderly people had not talked to anyone about their EOL preferences. ${ }^{6}$ Regarding the reasons for that, past theoretical studies argued that people avoid talking about death and dying since talking about EOL is a societal fear, ${ }^{7}$ and it is difficult to decide when it is appropriate to have a conversation about EOL, due to the ambiguity surrounding the topic, in that nobody can accurately predict when the time will come. ${ }^{89}$

However, concrete inhibiting and promoting factors of PCs about EOL among elderly people have not been clarified. Although a previous empirical study ${ }^{10}$ indicated that ageing is associated with promotion of PCs about EOL, its participants were not all elderly, but were 50 years or older. Thus, little is known about factors related to having PCs about EOL with close friends or family members among general elderly people who is defined as 65 years or older. ${ }^{11}$

We posit the following three hypotheses. First, having experience of PCs about EOL is associated with advancing age as older people are more likely to encounter an EOL situation. Second, experience of PCs about EOL tends to be decreased when the subjective economic status of older people is poor as they might find it difficult to have future prospects. ${ }^{12}$ Third, poor subjective health status is associated with experience of PCs about EOL as an advance directive is more frequently created among unhealthy elderly people than those in healthy status. ${ }^{13}$

The purpose of present study was to determine the inhibiting and promoting factors of PCs about EOL. Notably, Japan is one of the most economically developed and rapidly ageing countries in the world and pictures the future ageing situation in other countries. Therefore, we believe that studying the Japanese elderly population is beneficial to other developed countries.

\section{METHODS}

\section{Study design and sample}

In this cross-sectional study, a stratified random sampling method (figure 1) was used to select 3000 participants from the population of Koriyama City, Fukushima Prefecture, Japan, using the Japanese long-term care insurance system registry, which includes information regarding age, gender, presence or absence of nursing care and address of individuals aged 40 years or older living in Koriyama City. First, of the total elderly population, aged 65 years or older, of Koriyama City (84 030; 37382 males and 46648 females), residents who were not receiving nursing care as of November 1, 2016, were selected from the registry. This brought the number down to 78821 (33 958 males and 44863 females). Next, the potential subjects were stratified according to gender and 20 subregions based

\section{Population size of each stratum (sub-regions)}

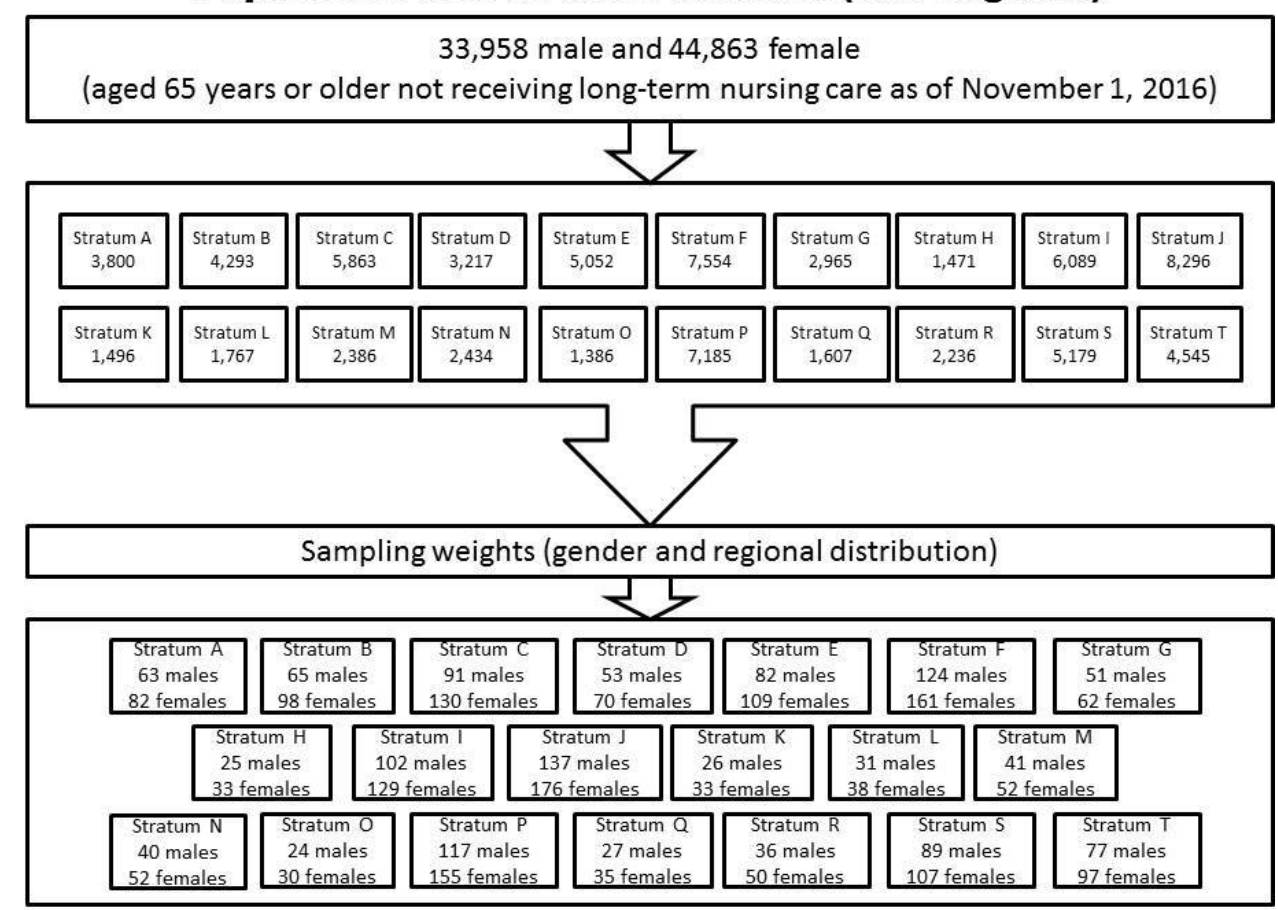

Figure 1 Sampling process of the study participants. Subjects were enrolled by stratified random sampling using sampling weights of gender and regional distribution from Koriyama City, Fukushima Prefecture, Japan. 
on Koriyama City's administrative boundaries. Sampling weights were then applied to adjust for gender and region distributions based on proportionate to the population size of elderly people. Finally, 1301 males $(43.4 \%)$ and 1699 females $(56.6 \%)$ were enrolled in the study.

In January 2017, we distributed questionnaires to the 3000 participants that included items covering demographic information and PCs-related factors. We also asked by whom the questionnaire was filled. In total, 2206 participants answered and returned the questionnaires anonymously (response rate $73.5 \%$ ). We excluded questionnaires that were answered by a person other than the participant, such as family members $(n=373)$, or that were answered incompletely $(n=301)$. The number of participants analysed in the present study was 1575 in total; 717 males $(45.5 \%)$ and 858 females $(54.5 \%)$. The effective response rate was $52.5 \%$.

\section{Measures \\ Basic attributes}

Basic attributes included age, gender, household composition and subjective economic status. Age was classified into two categories: 65-74 years ('early elderly') and 75 years or older ('late elderly'). Household composition was measured by choosing one of the following items: single person, couple (age of spouse was 65 years or older), couple (age of spouse was 64 years or younger), living with one or more sons or daughters and other. The degree of subjective economic status was assessed using a five-point scale (1='very good', 2='good', 3='fair', $4=$ 'poor' and $5=$ ='very poor').

\section{Health-related factors}

Subjective health status, subjective happiness and current/ past health problems were assessed using the following questions: 'How is your health now?' ( $1=$ =very good', $2=$ 'good', 3='bad' and 4='very bad'); 'How happy are you now?' (11 point scale: $1=$ 'mostly happy' to $11=$ 'mostly unhappy'); 'Please choose your current/past health problems (multiple answers allowed)', the options were nothing, hypertension, cerebrovascular diseases (such as stroke or cerebral infarction), heart diseases, diabetes, dyslipidaemia, respiratory diseases (such as pneumonia or bronchitis), gastrointestinal, liver and/or gallbladder diseases, kidney and/or prostate diseases, musculoskeletal diseases (such as osteoporosis or arthrosis), external injury (such as falling down or fracture), cancer, immunological and/or haematological diseases, depression, dementia, Parkinson's disease, eye diseases, ear nose throat diseases and other.

\section{Outcome}

The outcome was the presence of experience of having had PCs about EOL with family members and/or friends, and it was measured using the following question: 'Have you ever held a conversation about your EOL preferences with family members or close friends?' ('yes' or 'no').

\section{Statistical analysis}

Statistical analyses were performed using SPSS statistics V.24 (IBM Corp.), and the participants' characteristics were summarised using descriptive statistics. The associations between the above-mentioned factors and outcome variables were examined using a $\chi^{2}$ test or Mann-Whitney $\mathrm{U}$ test. The statistical significance of the cells in the tables was analysed using residual analysis after the $\chi^{2}$ test. Current/past health problems were classified into 0 or $\geq 1$ based on the number chosen in the question and then used in the statistical analysis.

Multivariable logistic-regression models were prepared to estimate the association between experience of PCs about EOL and potential promoting/inhibiting predictors, including the above-mentioned factors (stepwise forward selection based on likelihood ratio). Inclusion of variables in the models was based on our hypotheses and existing knowledge of PCs about EOL. Independent variables consisted of following basic attributes and health-related factors: age, gender, household composition (living alone or living with others), subjective economic status, subjective health status, subjective happiness and current/ past health problems $(\geq 1$ or 0$)$. Presence of experience of PCs about EOL was the dependent variable. The independent variables that were significantly associated with presence of experience of PCs about EOL were considered to be promoting factors, whereas those that were significantly associated with absence of experience of PCs about EOL were considered inhibiting factors.

The variance inflation factor (VIF) was used to test multicollinearity. The VIF values for age, gender, household composition, subjective economic status, subjective health status, subjective happiness and current/past health problems were $1.125,1.028,1.048,1.174,1.361$, 1.324 and 1.081, respectively. None of the VIF values were as high as 10 , and the mean VIF of the model was less than 6 . Thus, there was no collinearity.

$P$ values below 0.05 were regarded as statistically significant. The OR and 95\% CI were calculated using the regression analysis.

\section{Patient and public involvement}

We did not include patients as study participants. The participants were not involved in the development of research questions, design or conduct of this study, or the interpretation of the results.

\section{RESULTS}

The characteristics of the participants are shown in table 1 . The mean age of the participants was 74.0 years (SD: 6.87, range: $65-98)$, and the total number of early elderly and late elderly were $909(57.7 \%)$ and $666(42.3 \%)$, respectively. The most common answers for household composition, subjective economic status, subjective health status, current/past health problems and experience of PCs about EOL were 'couple (spouse was 65 years or older)' $(32.7 \%)$, 'fair' (62.9\%), 'good' (70.5\%), 'hypertension’ 


\begin{tabular}{|c|c|c|c|}
\hline Variables & $\begin{array}{l}\text { Total } \\
(n=1575)\end{array}$ & $\begin{array}{l}\text { Male } \\
(n=717)\end{array}$ & $\begin{array}{l}\text { Female } \\
(\mathrm{n}=858)\end{array}$ \\
\hline $\mathrm{Age} \pm \mathrm{SD}$ & $74.0 \pm 6.87$ & $73.5 \pm 6.75$ & $74.3 \pm 6.96$ \\
\hline Early elderly & $909(57.7)$ & $436(60.8)$ & $473(55.1)$ \\
\hline Late elderly & 666 (42.3) & $281(39.2)$ & $385(44.9)$ \\
\hline \multicolumn{4}{|l|}{ Household composition } \\
\hline Single person & $246(15.6)$ & $81(11.3)$ & $165(19.2)$ \\
\hline Couple ( $\geq 65$ spouse) & $515(32.7)$ & 274 (38.2) & $241(28.1)$ \\
\hline Couple (<65 spouse) & $80(5.1)$ & $61(8.5)$ & $19(2.2)$ \\
\hline $\begin{array}{l}\text { Living with one } \\
\text { or more sons or } \\
\text { daughters }\end{array}$ & $505(32.1)$ & $203(28.3)$ & $302(35.2)$ \\
\hline
\end{tabular}

\begin{tabular}{lccc}
$\begin{array}{l}\text { Others } \\
\text { Subjective economic status }\end{array}$ & & & \\
Very good & $11(0.7)$ & $8(1.1)$ & $3(0.3)$ \\
\hline Good & $76(4.8)$ & $43(6.0)$ & $33(3.8)$ \\
Fair & $991(62.9)$ & $408(56.9)$ & $583(67.9)$ \\
\hline Poor & $365(23.2)$ & $188(26.2)$ & $177(20.6)$ \\
\hline Very poor & $132(8.4)$ & $70(9.8)$ & $62(7.2)$
\end{tabular}

\section{Subjective health status}

\begin{tabular}{lccc} 
Very good & $176(11.2)$ & $82(11.4)$ & $94(11.0)$ \\
\hline Good & $1111(70.5)$ & $497(69.3)$ & $614(71.6)$ \\
\hline Bad & $263(16.7)$ & $125(17.4)$ & $138(16.1)$ \\
\hline Very bad & $25(1.6)$ & $13(1.8)$ & $12(1.4)$ \\
$\begin{array}{l}\text { Subjective happiness } \\
\text { (25-75 percentile) }\end{array}$ & $3(1-5)$ & $3(1-5)$ & $2(1-4)$ \\
\hline
\end{tabular}

Current/past health problems (multiple answers allowed)

\begin{tabular}{|c|c|c|c|}
\hline Nothing & $216(13.7)$ & $86(12.0)$ & $130(15.2)$ \\
\hline Hypertension & $680(43.2)$ & $314(43.8)$ & $366(42.7)$ \\
\hline $\begin{array}{l}\text { Cerebrovascular } \\
\text { diseases }^{*}\end{array}$ & $62(3.9)$ & $37(5.2)$ & 25 (2.9) \\
\hline Heart diseases & $148(9.4)$ & $82(11.4)$ & $66(7.7)$ \\
\hline Diabetes & $206(13.1)$ & $130(18.1)$ & 76 (8.9) \\
\hline Dyslipidaemia & $163(10.3)$ & $62(8.6)$ & $101(11.8)$ \\
\hline Respiratory diseases $†$ & $70(4.4)$ & $34(4.7)$ & $36(4.2)$ \\
\hline $\begin{array}{l}\text { Gastrointestinal } \\
\text { diseases } \ddagger\end{array}$ & $123(7.8)$ & $56(7.8)$ & $67(7.8)$ \\
\hline Kidney diseases§ & $130(8.3)$ & $121(16.9)$ & $9(1.0)$ \\
\hline $\begin{array}{l}\text { Musculoskeletal } \\
\text { diseases }\end{array}$ & $225(14.3)$ & $34(4.7)$ & $191(22.3)$ \\
\hline External injury ${ }^{\star *}$ & $55(3.5)$ & $19(2.6)$ & $36(4.2)$ \\
\hline Cancer & $64(4.1)$ & $36(5.0)$ & $28(3.3)$ \\
\hline $\begin{array}{l}\text { Immunological } \\
\text { diseasest† }\end{array}$ & $14(0.9)$ & $4(0.6)$ & $10(1.2)$ \\
\hline Depression & $13(0.8)$ & $3(0.4)$ & $10(1.2)$ \\
\hline Dementia & $6(0.4)$ & $2(0.3)$ & $4(0.5)$ \\
\hline Parkinson's disease & $9(0.6)$ & $5(0.7)$ & $4(0.5)$ \\
\hline Eye diseases & $357(22.7)$ & $142(19.8)$ & $215(25.1)$ \\
\hline $\begin{array}{l}\text { Ear nose throat } \\
\text { diseases }\end{array}$ & $84(5.3)$ & $37(5.2)$ & $47(5.5)$ \\
\hline
\end{tabular}

Continued

\begin{tabular}{clll|}
\hline Table 1 Continued & & & \\
\hline Variables & $\begin{array}{l}\text { Total } \\
(\mathbf{n}=1575)\end{array}$ & $\begin{array}{l}\text { Male } \\
(\mathbf{n}=717)\end{array}$ & $\begin{array}{l}\text { Female } \\
(\mathbf{n}=858)\end{array}$ \\
\hline Others & $111(7.0)$ & $47(6.6)$ & $64(7.5)$ \\
\hline
\end{tabular}

Experience possession of PCs about EOL

$\begin{array}{llll}\text { Possess } & 754(47.9) & 278(38.8) & 476(55.5) \\ \text { Not } & 821(52.1) & 439(61.2) & 382(44.5)\end{array}$

${ }^{*}$ Cerebrovascular diseases (such as stroke or cerebral infarction). †Respiratory diseases (such as pneumonia or bronchitis). $\ddagger$ Gastrointestinal, liver and/or gallbladder diseases. $\S$ Kidney and/or prostate diseases.

ПMusculoskeletal diseases (such as osteoporosis or arthrosis).

**External injury (such as falling down or fracture). ††Immunological and/or hematological diseases. EOL, end-of-life; PCs, pre-emptive conversations.

(43.2\%) and 'no' (52.1\%), respectively. The median of subjective happiness was 3 .

Bivariate analysis indicated that presence of experience of PCs about EOL was significantly associated with gender $(\mathrm{p}<0.001)$, subjective economic status $(\mathrm{p}=0.002)$ and subjective happiness $(\mathrm{p}<0.001)$, as shown in table 2 . Residual analysis revealed that the number of subjects who answered 'no' decreased when their subjective economic status was 'fair' $(49.5 \%)$ and increased when it was 'poor' $(58.6 \%)$ or 'very poor' $(60.6 \%)$. There were no significant associations between presence of experience of PCs about EOL and other factors such as age group ( $p=0.148)$, household composition $(\mathrm{p}=0.223)$, subjective health status $(p=0.066)$ or health problems $(p=0.159)$.

In table 3 , multivariable logistic-regression analysis revealed that presence of experience of PCs about EOL was significantly associated with gender $(\mathrm{OR}=1.907$; $95 \% \mathrm{CI}=1.556$ to $2.337 ; \mathrm{p}<0.001)$, subjective economic status $(\mathrm{OR}=0.832 ; 95 \% \mathrm{CI}=0.716$ to $0.966 ; \mathrm{p}=0.016)$ and subjective happiness $(\mathrm{OR}=0.926 ; 95 \% \mathrm{CI}=0.880$ to 0.973 ; $\mathrm{p}=0.003$ ). No statistical significances were found between experience of PCs about EOL and other factors such as age, household composition, subjective health status or health problems $(\mathrm{p}=0.171,0.161,0.448$ and 0.47 , respectively).

\section{DISCUSSION}

We conducted the study to determine the promoting/ inhibiting factors for PCs about EOL among elderly people. Contrary to our expectations, the results of the present study showed that female gender was a promoting factor and poor subjective economic status and happiness were inhibiting factors of PCs about EOL, and that there was no association between subjective health status and experience of PCs about EOL. Importantly, poor subjective economic status was associated to the absence of experience of PCs about EOL. Due to such absence, elderly people's EOL preferences may not be understood or respected during their EOL period, which may lead to trouble. 

Table 2 Associations of experience of PCs about EOL with
basic attributes and health-related factors

Experience possession of PCs about EOL

\begin{tabular}{|c|c|c|c|}
\hline Variables & Possess & Not & $P$ value \\
\hline \multicolumn{4}{|l|}{ Basic attributes } \\
\hline \multicolumn{3}{|l|}{ Gender } & $<0.001$ \\
\hline Male & $278(38.8)$ & $439(61.2)$ & \\
\hline Female & $476(55.5)$ & $382(44.5)$ & \\
\hline \multicolumn{3}{|l|}{ Age group } & 0.148 \\
\hline Early elderly & $421(46.3)$ & $488(53.7)$ & \\
\hline Late elderly & $333(50.0)$ & $333(50.0)$ & \\
\hline \multicolumn{3}{|c|}{ Household composition } & 0.223 \\
\hline Living alone & $109(44.3)$ & $137(55.7)$ & \\
\hline Living with others & $645(48.5)$ & $684(51.5)$ & \\
\hline \multicolumn{3}{|c|}{ Subjective economic status } & 0.002 \\
\hline Very good & $7(63.6)$ & $4(36.4)$ & \\
\hline Good & $44(57.9)$ & $32(42.1)$ & \\
\hline Fair & $500(50.5)^{\star}$ & $491(49.5) \dagger$ & \\
\hline Poor & $151(41.4) \dagger$ & $214(58.6)^{\star}$ & \\
\hline Very poor & $52(39.4) \dagger$ & $80(60.6)^{\star}$ & \\
\hline \multicolumn{4}{|l|}{ Health-related factors } \\
\hline \multicolumn{3}{|c|}{ Subjective health status } & 0.066 \\
\hline Very good & $97(55.1)$ & $79(44.9)$ & \\
\hline Good & $531(47.8)$ & $580(52.2)$ & \\
\hline $\mathrm{Bad}$ & $118(44.9)$ & $145(55.1)$ & \\
\hline Very bad & $8(32.0)$ & $17(68.0)$ & \\
\hline $\begin{array}{l}\text { Subjective } \\
\text { happiness }\end{array}$ & $2(1-4)$ & $3(1-5)$ & $<0.001$ \\
\hline \multicolumn{3}{|c|}{ Current/past health problems } & 0.159 \\
\hline 0 & $113(52.3)$ & $103(47.7)$ & \\
\hline$\geq 1$ & $641(47.2)$ & 718 (52.8) & \\
\hline
\end{tabular}

All categorical variables were examined using a $\chi^{2}$ test. Subjective happiness was examined using the Mann-Whitney $U$ test.

${ }^{*}$ Indicates adjusted standardised residual $>1.96$.

†Indicates adjusted standardised residual $<-1.96$.

EOL, end-of-life; PCs, pre-emptive conversations.

The association between female gender and experience of PCs about EOL may be explained by gender differences in conversation characteristics revealed by previous studies; females have been reported to disclose more information in general, ${ }^{14}$ refer more to topics that are intimate or personal ${ }^{15}$ and be more reflective than males. ${ }^{16}$ In light of these studies, it can be considered that females may have more opportunities to talk about their preferences compared with males, and that such increased opportunity for talks may contribute to increase the experience of PCs about EOL.

Consistent with our hypothesis, the number of participants with experience of PCs about EOL decreased as
Table 3 Logistic-regression analysis for the associations of experience of PCs about EOL with basic attributes and health-related factors

\begin{tabular}{|c|c|c|c|}
\hline \multirow[b]{2}{*}{ Variables } & \multicolumn{3}{|c|}{ Experience of PCs about EOL (possess) } \\
\hline & ORs $(95 \% \mathrm{Cl})$ & SE & $P$ value \\
\hline Gender (female) & 1.907 (1.556 to 2.337$)$ & 0.104 & $<0.001$ \\
\hline $\begin{array}{l}\text { Subjective } \\
\text { economic status }\end{array}$ & 0.832 (0.716 to 0.966$)$ & 0.076 & 0.016 \\
\hline $\begin{array}{l}\text { Subjective } \\
\text { happiness }\end{array}$ & 0.926 (0.880 to 0.973$)$ & 0.026 & 0.003 \\
\hline Age & $\mathrm{N} / \mathrm{A}$ & $\mathrm{N} / \mathrm{A}$ & 0.171 \\
\hline $\begin{array}{l}\text { Household } \\
\text { composition (living } \\
\text { with others) }\end{array}$ & N/A & N/A & 0.161 \\
\hline $\begin{array}{l}\text { Need for nursing } \\
\text { care (needed) }\end{array}$ & N/A & N/A & 0.391 \\
\hline $\begin{array}{l}\text { Subjective health } \\
\text { status }\end{array}$ & $\mathrm{N} / \mathrm{A}$ & N/A & 0.448 \\
\hline $\begin{array}{l}\text { Current/past health } \\
\text { problems }(\geq 1)\end{array}$ & $\mathrm{N} / \mathrm{A}$ & $\mathrm{N} / \mathrm{A}$ & 0.47 \\
\hline
\end{tabular}

N/A indicates 'not applicable', because no statistical differences were observed for the variables using the stepwise method. EOL, end-of-life; PCs, pre-emptive conversations.

the subjective economic status worsened. Good subjective economic status may motivate elderly people to build relationships with others and activate conversations such as PC. According to a previous study, good subjective economic status was associated with active social participation among the elderly. ${ }^{17}$ Importantly, elderly people with poor subjective economic status may not have such conversations enough times, and thus their EOL preferences may not be understood or respected by family or close friends in an actual EOL situation.

Contrary to our hypothesis, poor subjective happiness was associated with absence of experience of PCs about EOL. Elderly people with poor subjective happiness might feel reluctant to talk about themselves, and thus PCs about EOL might be procrastinated. Previous studies have revealed that procrastination is associated to psychological problems such as depression, ${ }^{18}{ }^{19}$ anxiety ${ }^{20}$ and high levels of stress. ${ }^{21}$ Moreover, other past studies indicated that the presence of such psychological problems was associated with decreased happiness. ${ }^{22-24}$ In light of these studies, it is assumed that poor subjective happiness among the subjects of our study may be explained by the procrastination. Moreover, Karas and Spada reported that brief cognitive-behavioural coaching has a positive effect on procrastination ${ }^{25}$; therefore, step-by-step motivational support from a psychologist may contribute to the promotion of PCs about EOL among the elderly.

Promotion of PCs about EOL may contribute to Advanced Care Planning, ACP. ACP is defined as a process in which the elderly people confirm and share personal intentions for EOL care. ${ }^{26}$ In contrast, PCs about EOL can include a broad range of topics ${ }^{27} 28$ other than those 
related to 'care'. It is assumed that the information gathered from PCs about EOL is beneficial for understanding elderly individuals' values; such information is expected to be a foundation of ACP.

Association between economic status and PCs about EOL in Japan may be consistent with that in other countries. A past study in USA reported a similar result to our study in regard to the association between low income and low completion of EOL planning. ${ }^{6}$ The fact that such similar result was shown across Asian and American subjects is considered to be important, when they have different beliefs/concerns on medical decisions including EOL care choices such as an emphasis on financial burden of caregiving on their family in Japanese ${ }^{29}$ and on autonomy of individuals in American/Western European. ${ }^{30}$ Economic status may be a possible common factor of PCs about EOL regardless of culture, although overgeneralisation should be taken into account.

The present study has following two limitations. First, the study population was from a single city in Japan. While we employed stratified random sampling to reduce sampling bias, future studies should be conducted using subjects from multiple regions in order to improve the representativeness of the study population. Second, as reported in a Baker's past review, ${ }^{31}$ low economic status may influence not only PCs about EOL but also EOL care choices; however, our data did not include the information regarding EOL care choices. Future studies should be designed to examine the associations between economic status, PCs about EOL and EOL care choices.

In conclusion, we determined the promoting and inhibiting factors for PCs about EOL among elderly people, and found that female gender was a promoting factor, and that poor subjective economic status and happiness were inhibiting factors. Disparity in experience of PCs about EOL may be caused by subjective economic status among elderly people, and it should be of concern that EOL care preferences of elderly people without PC experience may not be fully understood or respected. To promote PCs about EOL among elderly people, gerontology and public health professionals should give special consideration to the subjective economic status of elderly people.

\section{Author affiliations}

${ }^{1}$ Department of Hygiene and Preventive Medicine, Fukushima Medical University, Fukushima, Japan

${ }^{2}$ Division of Children, Hoshi General Hospital Foundation, Fukushima, Japan

${ }^{3}$ Director, Koriyama City Public Health Center, Fukushima, Japan

Contributors TH designed this study, analysed the data and wrote the manuscript. KS and KA designed this study and collected the data. TKakamu, SE, HK, YM and TKumagai also designed this study and contributed to the analysis. TF critically revised the manuscript. All authors read and approved the final version of the manuscript.

Funding The authors have not declared a specific grant for this research from any funding agency in the public, commercial or not-for-profit sectors.

Competing interests None declared.

Patient consent for publication Not required.
Ethics approval This study was approved by the Ethics Committee of Fukushima Medical University (application no. 29047).

Provenance and peer review Not commissioned; externally peer reviewed.

Data availability statement No additional data are available for this study. However, inquiries concerning the data may be made to the corresponding author.

Open access This is an open access article distributed in accordance with the Creative Commons Attribution Non Commercial (CC BY-NC 4.0) license, which permits others to distribute, remix, adapt, build upon this work non-commercially, and license their derivative works on different terms, provided the original work is properly cited, appropriate credit is given, any changes made indicated, and the use is non-commercial. See: http://creativecommons.org/licenses/by-nc/4.0/.

ORCID iDs

Tomoo Hidaka http://orcid.org/0000-0003-2987-4804

Takeyasu Kakamu http://orcid.org/0000-0001-6920-8457

\section{REFERENCES}

1 Emanuel EJ, Emanuel LL. Proxy decision making for incompetent patients. An ethical and empirical analysis. JAMA 1992;267:2067-71.

2 Silveira MJ, Kim SYH, Langa KM. Advance directives and outcomes of surrogate decision making before death. N Engl J Med 2010;362:1211-8.

3 Braun UK, Beyth RJ, Ford ME, et al. Voices of African American, Caucasian, and Hispanic surrogates on the burdens of end-of-life decision making. J Gen Intern Med 2008;23:267-74.

4 Rafferty KA, Cramer EM, Priddis D. Managing end-of-life uncertainty: applying problematic integration theory to spousal communication about death and dying. Am J Hosp Palliat Care 2016;33:69-76.

5 Ko E, Lee J. End-Of-Life communication: ethnic differences between Korean American and non-Hispanic white older adults. J Aging Health 2009;21:967-84.

6 Harrison KL, Adrion ER, Ritchie CS, et al. Low completion and disparities in advance care planning activities among older Medicare beneficiaries. JAMA Intern Med 2016;176:1872-5.

7 Omilion-Hodges L, Swords N. Communication matters: exploring the intersection of family and practitioner end of life communication. Behav Sci 2017;7:15.

8 Babrow AS. Communication and problematic integration: Milan Kundera's "lost letters" in the book of laughter and forgetting. Commun Monogr 1995;62:283-300.

9 Bradac JJ. Theory comparison: uncertainty reduction, problematic integration, uncertainty management, and other curious constructs. $J$ Commun 2001;51:456-76.

10 Orimo $\mathrm{H}$, Ito $\mathrm{H}$, Suzuki T, et al. Reviewing the definition of "elderly". Geriatr Gerontol Int 2006;6:149-58.

11 World Health Organization. Definition of an older or elderly person. Available: http://www.who.int/healthinfo/survey/ageingdefnolder/en/ index.html [Accessed 25 Jul 2018].

12 Nobles J, Weintraub MR, Adler NE. Subjective socioeconomic status and health: relationships reconsidered. Soc Sci Med 2013;82:58-66.

13 Ditto PH, Jacobson JA, Smucker WD, et al. Context changes choices: a prospective study of the effects of hospitalization on life-sustaining treatment preferences. Med Decis Making 2006;26:313-22.

14 Reisman JM. Intimacy in same-sex friendships. Sex Roles 1990;23:65-82.

15 Aries EJ, Johnson FL. Close friendship in adulthood: Conversational content between same-sex friends. Sex Roles 1983;9:1183-96.

16. Skultety KM, Krauss Whitbourne S, Whitbourne SK. Gender differences in identity processes and self-esteem in middle and later adulthood. J Women Aging 2004;16:175-88.

17 Nemoto Y, Nonaka K, Hasebe M, et al. Factors that promote new or continuous participation in social group activity among Japanese community-dwelling older adults: a 2-year longitudinal study. Geriatr Gerontol Int 2018;18:1259-66.

18 Solomon LJ, Rothblum ED. Academic procrastination: frequency and cognitive-behavioral correlates. J Couns Psychol 1984;31:503-9.

19 Rothblum ED, Solomon LJ, Murakami J. Affective, cognitive, and behavioral differences between high and low procrastinators. $J$ Couns Psychol 1986;33:387-94.

20 Lay $\mathrm{CH}$, last $\mathrm{A}$. At last, my research article on procrastination. $J$ Res Pers 1986;20:474-95.

21 Tice DM, Baumeister RF. Longitudinal study of procrastination, performance, stress, and health: the costs and benefits of Dawdling. Psychol Sci 1997;8:454-8. 
22 Marrero Quevedo RJ, Carballeira Abella M, Marrero RJ. WellBeing and personality: Facet-level analyses. Pers Individ Dif 2011;50:206-11.

23 Spinhoven P, Elzinga BM, Giltay E, et al. Anxious or depressed and still happy? PLoS One 2015;10:e0139912.

24 Schiffrin HH, Nelson SK. Stressed and happy? investigating the relationship between Happiness and perceived stress. J Happiness Stud 2010;11:33-9.

25 Karas D, Spada MM. Brief cognitive-behavioural coaching for procrastination: a case series. Coaching: An International Journal of Theory, Research and Practice 2009;2:44-53.

26 Sudore RL, Lum HD, You JJ, et al. Defining advance care planning for adults: a consensus definition from a multidisciplinary Delphi panel. J Pain Symptom Manage 2017;53:821-32.
27 Institute for Healthcare Improvement. National healthcare decisions day, 2012. Available: https://www.nhdd.org/ [Accessed 8 Aug 2019].

28 The Conversation Project. The conversation project - have you had the conversation? 2019. Available: http://theconversationproject.org/ [Accessed 8 Aug 2019].

29 Bito S, Matsumura S, Singer MK, et al. Acculturation and end-of-life decision making: comparison of Japanese and Japanese-American focus groups. Bioethics 2007;21:251-62.

30 Searight HR, Gafford J. Cultural diversity at the end of life: issues and guidelines for family physicians. Am Fam Physician 2005;71:515-22.

31 Baker ME. Economic, political and ethnic influences on end-oflife decision-making: a decade in review. $J$ Health Soc Policy 2002;14:27-39. 